\title{
One Pot Synthesis of CoTiO3- TiO2 Composite Nanofibers and its Application in Dye Degradation
}

\author{
M. Shamshi Hassan, Department of Chemistry, Albaha University, Saudi Arabia
}

\begin{abstract}
$\mathrm{CoTiO}_{3}-\mathrm{TiO}_{2}$ composite nanofibrous photocatalysts were synthesized by means of the one-step electrospinning method. The samples were characterized by a range of different methods (XRD, SEM, EPMA, FT-IR, UV-DRS, and TEM). Photocatalytic activity was performed for the degradation of rhodamine $6 \mathrm{G}$ under visible light. The results showed that $\mathrm{CoTiO}_{3}-\mathrm{TiO}_{2}$ composite photocatalysts were successfully synthesized. The average sizes of the diameters of the composite nanofibers were found to be 300 to $400 \mathrm{~nm}$. The $\mathrm{UV}-\mathrm{Vis}$ diffuse reflectance spectra of the $\mathrm{CoTiO}_{3}-\mathrm{TiO}_{2}$ composite showed an absorption wavelength, in the visible light region, having a band gap energy value of 2.21 $\mathrm{eV}$. The $\mathrm{CoTiO}_{3}-\mathrm{TiO}_{2}$ composite showed higher photocatalytic efficiency than that of pristine $\mathrm{TiO}_{2}$; which can be attributed to the heterojunctional interaction between $\mathrm{CoTiO}_{3}$ and $\mathrm{TiO}_{2}$.
\end{abstract}

\section{KEYWORDS}

Composite, $\mathrm{CoTiO}_{3}-\mathrm{TiO}_{2}$, Electrospinning, Nanofibers

\section{INTRODUCTION}

Water pollution is a matter of great concern in society. Photocatalysts are applied in order to degrade harmful organic pollutants into non-toxic compounds in water (Zhang et al., 2012). $\mathrm{TiO}_{2}$ is one of the best-known photocatalysts so far. However, $\mathrm{TiO}_{2}$ has a notable limitation in that its energy band falls in the ultraviolet zone, which makes it unsuitable to be applied for use in photodegradation under visible light. A lot of effort has been done in this regard in order to extend its activity in the visible region, by making various modifications. Scientists have shown immense curiosity in developing the modified titania; having its wavelength absorption in visible light region. One of the usual procedures is the doping of $\mathrm{TiO}_{2}$ with elements like carbon, sulfur, and nitrogen; etc. (Chen, Jiang, Geng, Wang, \& Yang, 2007; Guan et al., 2019; Ida et al., 2019; Luna, Gatica, Vidal, \& Mosquera, 2019; Mahy et al., 2019; Park, Kim, \& Bard, 2006; Pylnev \& Wong, 2019; Sheydaei, Zangouei, \& Vatanpour, 2019; Srisasiwimon, Chuangchote, Laosiripojana, \& Sagawa, 2018; Tasbihi et al., 2019; Yoon et al., 2018). An alternative method is to combine $\mathrm{TiO}_{2}$ with a semiconductor having a small bandwidth (Abdi, Yahyanezhad, Sakhaie, Vossoughi, \& Alemzadeh, 2019; Chanhom, Charoenlap, Manipuntee, \& Insin, 2019; Hendrix, Lazaro, Yu, \& Brouwers, 2019; Ilieva, Nakova, \& Tsakova, 2012; Jiang et al., 2018; Mahieu, Puzenat, Geantet, Cardenas, \& Afanasiev, 2019; Mao et al., 2017; Ouyang,

\section{DOI: 10.4018/IJCCE.2019070105}

This article published as an Open Access article distributed under the terms of the Creative Commons Attribution License (http://creativecommons.org/licenses/by/4.0/) which permits unrestricted use, distribution, and production in any medium, provided the author of the original work and original publication source are properly credited. 
Chang, \& Li, 2012; Ratova, Tosheva, Kelly, \& Ohtani, 2019). By joining two semiconductors, a new photocatalytic material with a modified band gap can be developed, which will not merely lengthen the absorption of light to the visible spectrum but will, as well, put a check on the fast merging of electrons or holes during photoactivity.

Metal titanates like nickel titanate, cobalt titanate, ferrite titanate, zinc titanate, copper titanate, and lead titanate are famous functional materials which possess an assortment of uses. The titanate perovskites are the best recommended materials for use in photodegradation. Generally, titanate perovskites having band energy of $(>3.0 \mathrm{eV})$ show photocatalytic activity under UV (ultraviolet) light (Ke, Cheng, Wang, Wang, \& Pan, 2014; Zhu, Anzai, Yamamoto, \& Yoshida, 2019). By doping the metal titanates, their wavelength can be modified from the UV to the visible light absorption range. $\mathrm{CoTiO}_{3}$ is an $\mathrm{ABO}_{3}$-type perovskite oxide, having a narrow band gap semiconductor. Cobalt titanate $\left(\mathrm{CoTiO}_{3}\right)$ has been used in various applications such as Li-ion batteries (Jiang et al., 2014), gas sensors (Chuang et al., 2010), magnetic recorders (Toubal, Bensaha, \& Yakuphanoglu, 2017) and photocatalysts (Wang, Guo, Wang, \& Li, 2016). Cobalt titanate possesses a band width the in visible range $(\mathrm{Eg}=2.28 \mathrm{eV})$. Currently, $\mathrm{CoTiO}_{3}$ has been used as a catalyst under visible light (Singh et al., 2019). In the last few years, one-dimensional nanomaterials have gotten a tremendous response because of their unique size and shape. Developing materials with 1D (one-dimensional) morphology and nano-size range will not only increase their surface area but will also improve their properties. Therefore, it is believed that 1D nano-structures will exhibit superior thermal, optical, or electrical properties as compared to their nanoparticle counterparts (Choi, Kim, Lim, \& Park, 2010; Pan et al., 2012).

The objective of the author's investigation was to synthesize one-dimensional $\mathrm{TiO}_{2}-\mathrm{CoTiO}_{3}$ nanofibers by means of one-pot electrospinning. The crystal structure and surface organization of the $\mathrm{CoTiO}_{3}-\mathrm{TiO}_{2}$ nanofibers have been described by different methods. Moreover, the photoactivity of the $\mathrm{CoTiO}_{3}-\mathrm{TiO}_{2}$ nanofibers were also examined. The $\mathrm{CoTiO}_{3}-\mathrm{TiO}_{2}$ composite showed better photodegradation efficiency as compared to pristine $\mathrm{TiO}_{2}$. This might be ascribed to the heterojunctional interaction between $\mathrm{CoTiO}_{3}$ and $\mathrm{TiO}_{2}$.

\section{EXPERIMENTAL WORK}

\section{Preparation of the $\mathrm{CoTiO}_{3}-\mathrm{TiO}_{2}$ Nanofibers}

Fabrication of $\mathrm{CoTiO}_{3}-\mathrm{TiO}_{2}$ composite nanofiber was done via a one-step electrospinning method. Solution of $18 \mathrm{wt} \%$ Poly(vinyl acetate) (PVAc) was made in $N, N$-dimethylformamide (DMF) at 25 ${ }^{\circ} \mathrm{C}$. Titanium isopropoxide $(5 \mathrm{~g})$ with some drops of acetic acid and homogeneous mixture of ethanol and $\mathrm{Co}\left(\mathrm{NO}_{3}\right)_{3} \cdot 6 \mathrm{H}_{2} \mathrm{O}(1 \mathrm{~g})$ was added in a beaker. This solution was mixed with PVAc solution (6 $\mathrm{ml}$ ), and the author kept on stirring it. The resultant sol-gel was electrospun at $15 \mathrm{kV}$. The fibrous mat was evaporated at $80{ }^{\circ} \mathrm{C}$ overnight and heated at $500{ }^{\circ} \mathrm{C}$ for 2 hours in standard atmosphere. PVAc was chosen as a template because of its easy availability, hydrophobicity, and its having no designed crosslinks. A new hybrid organic-inorganic solution was obtained by means of a chemical crosslinking reaction among titanium, cobalt precursor, and polyvinyl acetate. The experiment was done in $N, N$-dimethylformamide solution, by an organized crosslinking procedure which results in a uniform and clear solution.

Synthesis of pristine $\mathrm{TiO}_{2}$ nanofibers was also done by dissolving titanium isopropoxide $(5 \mathrm{~g})$ with some drops of acetic acid in PVAc polymer solution $(6 \mathrm{ml})$. The synthesized mat was oven-dried calcined at $500{ }^{\circ} \mathrm{C}$ in a muffle furnace.

\section{Characterization}

$\mathrm{X}$-ray data of pure and composite nanofibers was examined by a Rigaku/Max-3A X-ray diffractometer having an angle range of 20 to $80^{\circ}$. The microstructure was examined by SEM (JSM6700, JEOL, 
Japan) and TEM (H-7650 Hitachi, Co., Japan). The UV-DRS of powder samples were measured by Shimadzu spectrophotometer (UV-2501PC). The elemental distribution of samples was recorded by electron probe microanalysis (EPMA).

\section{Photocatalytic Reaction}

The photodegradation activity of $\mathrm{TiO}_{2}$ and $\mathrm{CoTiO}_{3}-\mathrm{TiO}_{2}$ composite fibers was studied by the degradation of rhodamine $6 \mathrm{G}(\mathrm{R} 6 \mathrm{G})$ in visible lamp. The photoactivity was done by dissolving $100 \mathrm{mg}$ of the sample into a solution comprised of $100 \mathrm{ml}$ of water and $10 \mathrm{ppm}$ of dye. Prior to photocatalysis, the suspension was stirred in dark conditions for 30 minutes to establish absorption-desorption equilibrium with photocatalyst and rhodamine $6 \mathrm{G}$ dye. The nanofibers were added into the R6G solution and irradiated by a 125-W fluorescent mercury lamp having a UV filter of $(\lambda>400 \mathrm{~nm})$. The concentration of R6G in solution was pipetted out in fixed time intervals. The photocatalytic activity of $\mathrm{TiO}_{2}$ and $\mathrm{CoTiO}_{3}-\mathrm{TiO}_{2}$ composite nanofibers was compared.

\section{RESULTS AND DISCUSSION}

Figure 1 exhibits the $\mathrm{XRD}$ spectra of the calcined $\mathrm{TiO}_{2}$ - and $\mathrm{TiO}_{2}$-coupled $\mathrm{CoTiO}_{3}$ nanofibers. In Figure 1a, the characteristics of the X-ray peaks of the (101) (103) (004) (112) (200) (105) (211) (204) (116) reflections could be indexed for anatase $\mathrm{TiO}_{2}$ phase (JCPDS no. 894921) ( $\mathrm{Li}$ et al., 2013). No other peaks have been noticed in the spectra; therefore, this confirms its high purity-whereas, in Figure 1b, characteristics of the X-ray peaks of the (104) and (110) reflections attributed to the $\mathrm{CoTiO}_{3}$ (JCPDS no. 330960) together with the anatase $\mathrm{TiO}_{2}$ phase. Figures $2 \mathrm{a}$ and $2 \mathrm{~b}$ demonstrate the SEM pictures of the fabricated $\mathrm{TiO}_{2}$ and $\mathrm{CoTiO}_{3}-\mathrm{TiO}_{2}$ nanofibers, respectively. The $\mathrm{TiO}_{2}$ nanofibers show even and smooth surfaces having an average diameter of 500-600 nm (Figure 2a); whereas, the $\mathrm{CoTiO}_{3}$ $\mathrm{TiO}_{2}$ composite nanofibers demonstrated a granular structure with a smaller diameter. The average diameter was found to be $300-400 \mathrm{~nm}$ (Figure 2b). Formation of the $\mathrm{CoTiO}_{3}-\mathrm{TiO}_{2}$ composite was further confirmed from EPMA dot images (Figure 3). The EPMA pictures noticeably demonstrated the homogenous presence of $\mathrm{Co}, \mathrm{Ti}$, and $\mathrm{O}$, which were distributed over the composite's surface.

The simple TEM and high-resolution TEM images of the $\mathrm{CoTiO}_{3}-\mathrm{TiO}_{2}$ composite nanofibers were shown in Figure 4. The TEM image in Figure 4a shows the distribution of black particles along

Figure 1. XRD pattern of synthesized: (a) TiO2; and (b) CoTiO3-TiO2 nanofibers calcined at $500{ }^{\circ} \mathrm{C}$ for 2 hours

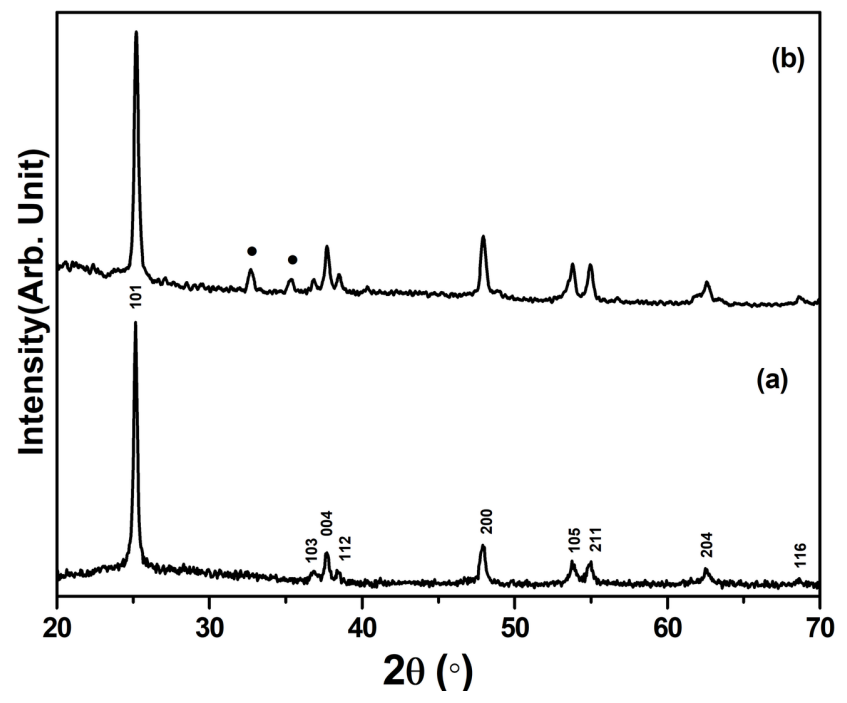


Figure 2. SEM image of synthesized: (a) TiO2; and (b) CoTiO3-TiO2 nanofibers calcined at $500{ }^{\circ} \mathrm{C}$ for 2 hours

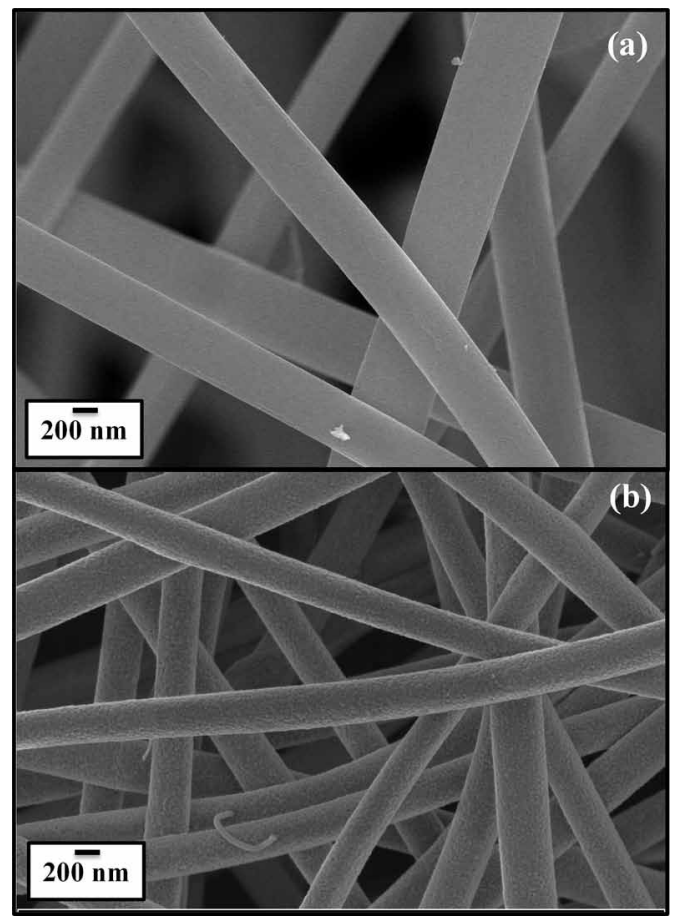

Figure 3. EPMA spectra of synthesized CoTiO3-TiO2 composite nanofibers

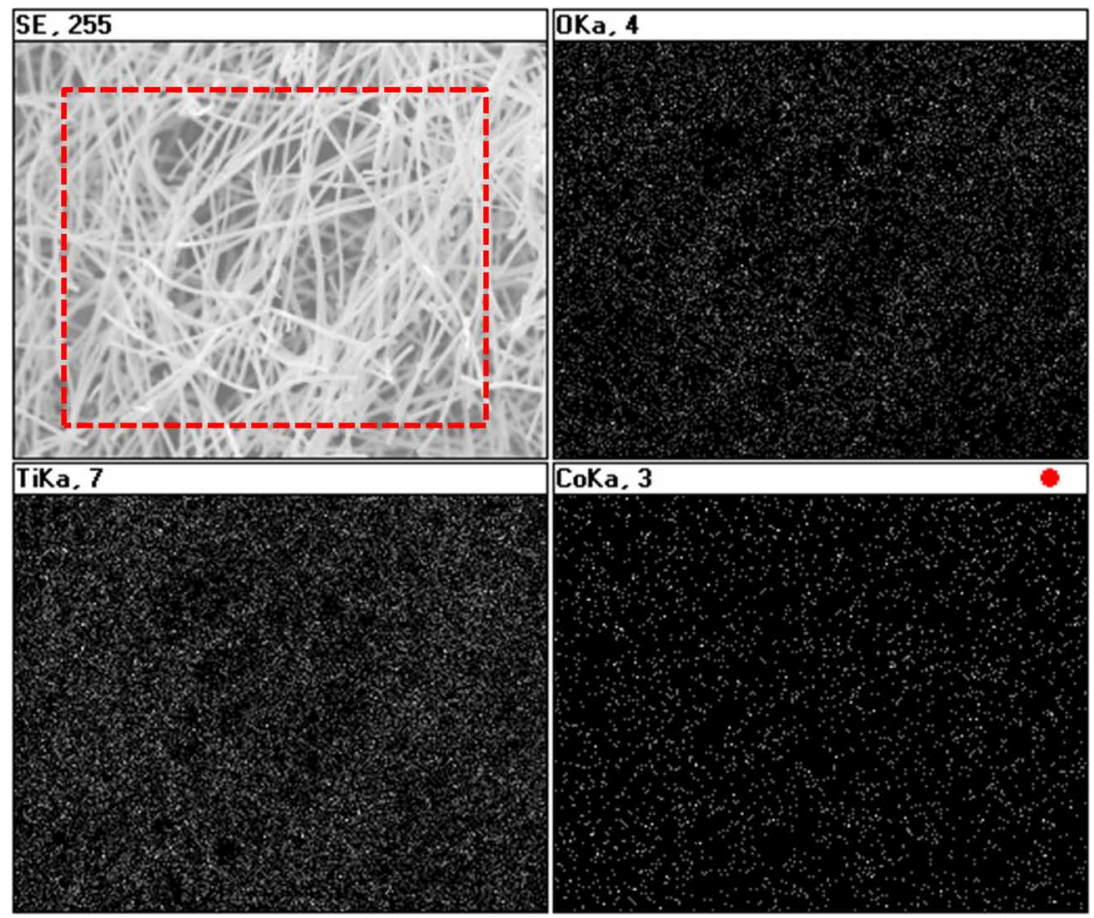


Figure 4. (a) HR-TEM; and (b) TEM micrographs of $\mathrm{CoTiO}_{3}-\mathrm{TiO}_{2}$ composite nanofibers

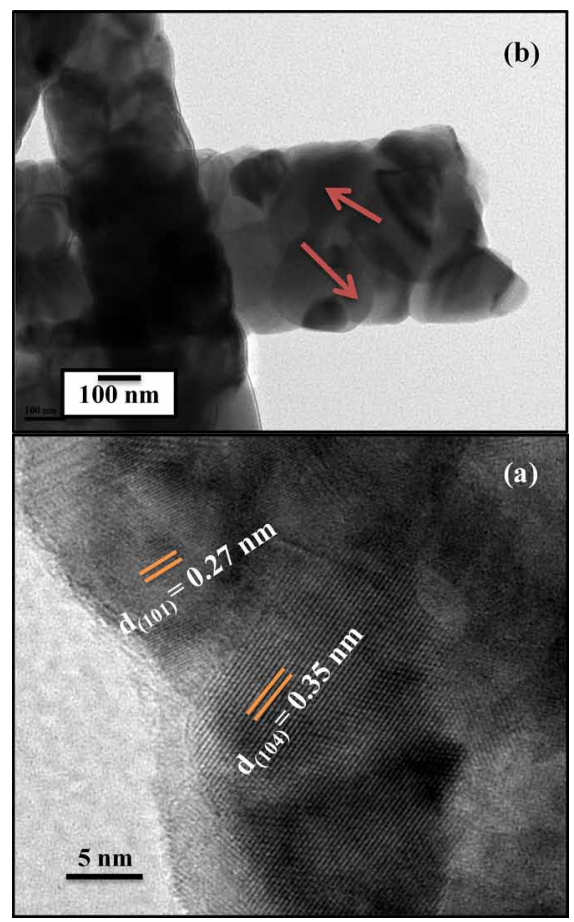

with the nanofibers. Upon closer inspection of the microstructure of these particles by HR-TEM, the presence of crystalline $\mathrm{CoTiO}_{3}$ with $\mathrm{TiO}_{2}$ (Figure 4b) has been confirmed. For $\mathrm{CoTiO}_{3}$, the interatomic spacing of the lattice plane (104) was found to be $0.27 \mathrm{~nm}$; whereas for $\mathrm{TiO}_{2}$, the spacing for the lattice plane (101) was $0.35 \mathrm{~nm}$.

The molecular structure of the pure $\mathrm{TiO}_{2}$ and composite $\mathrm{CoTiO}_{3}-\mathrm{TiO}_{2}$ nanofibers has been characterized by FTIR spectroscopy (Figure 5) after calcination. FTIR spectra showed the total

Figure 5. FT-IR spectra of synthesized: (a) $\mathrm{TiO}_{2}$; and (b) $\mathrm{CoTiO}_{3}-\mathrm{TiO}_{2}$ composite nanofibers

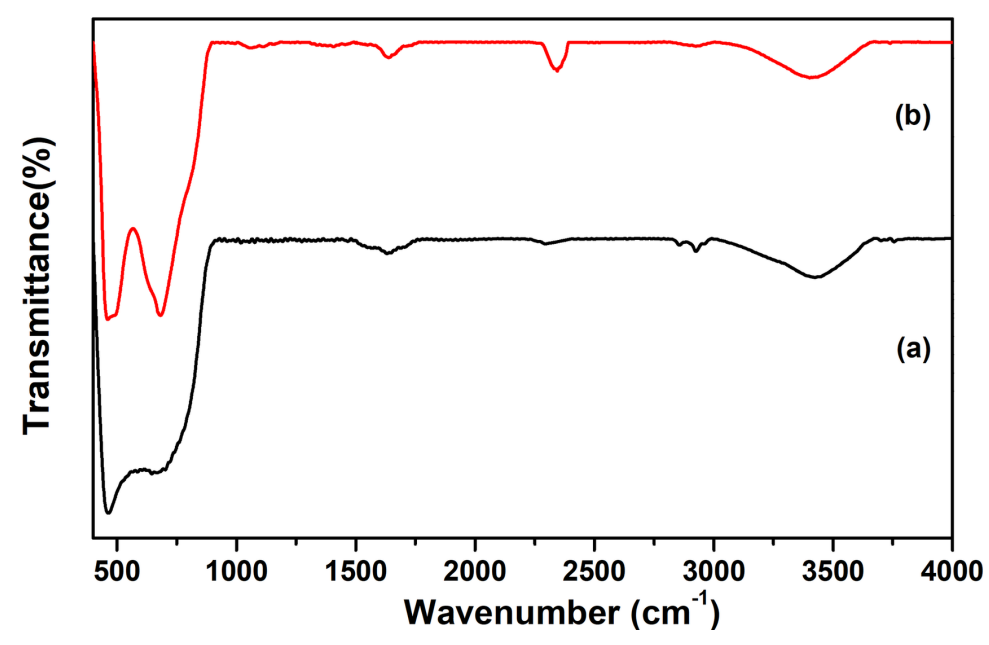


removal of the unwanted organics and the formation of metal oxide. Thus, above $2000 \mathrm{~cm}^{-1}$, a very broad absorption peak around $3420 \mathrm{~cm}^{-1}$ endorsed to the $-\mathrm{OH}$ stretching vibration mode was detected for both samples. A minor peak at $1635 \mathrm{~cm}^{-1}$ was observed due to the bending vibrations of absorbed molecular water. For both the samples of $\mathrm{TiO}_{2}$ and $\mathrm{CoTiO}_{3}-\mathrm{TiO}_{2}$, the presence of a major peak before $1000 \mathrm{~cm}^{-1}$ is noticed. The absorption peaks between 400 and $1000 \mathrm{~cm}^{-1}$ could be allocated to the vibration of ions of metal. The aforementioned peaks were related to the stretching mode of $\mathrm{Co}-\mathrm{O}$ and $\mathrm{Ti}-\mathrm{O}$, corresponding to the presence of titania and cobalt titanate (Hashemian \& Foroghimoqhadam, 2014; Yan, He, Evans, Zhu, \& Duan, 2004).

Figure 6 shows the UV-DRS of pristine $\mathrm{TiO}_{2}$ and nanocomposite $\mathrm{CoTiO}_{3}-\mathrm{TiO}_{2}$ nanofibers. As depicted here, the $\mathrm{TiO}_{2}$ nanofibers possess an absorption edge at $387 \mathrm{~nm}$; and for the $\mathrm{CoTiO}_{3}-\mathrm{TiO}_{2}$ nanocomposite nanofibers, it appeared at $560 \mathrm{~nm}$. The pure $\mathrm{TiO}_{2}$ has demonstrated the spectra in the ultraviolet region; whereas the $\mathrm{CoTiO}_{3}-\mathrm{TiO}_{2}$ nanocomposite revealed extended optical absorption in the visible region. The spectra of $\mathrm{CoTiO}_{3}-\mathrm{TiO}_{2}$ nanocomposites demonstrated the combination of the spectra of $\mathrm{CoTiO}_{3}$ and $\mathrm{TiO}_{2}$. It is known that $\mathrm{TiO}_{2}$ absorbs UV light only. So, it can be said that the absorbance in the visible region is mainly because of the $\mathrm{CoTiO}_{3}$ in the composite. The calculated band energy of the $\mathrm{TiO}_{2}$ nanofibers is $3.2 \mathrm{eV}$, whereas the band gap of the $\mathrm{CoTiO}_{3}-\mathrm{TiO}_{2}$ composite is $2.21 \mathrm{eV}$. For $\mathrm{TiO}_{2}$, the position of the conduction band is around $\sim 0.3 \mathrm{eV}$; and the position of the valence band is around $\sim 2.9 \mathrm{eV}$ (Tahir \& Amin, 2013). Meanwhile, the band gap of $\mathrm{CoTiO}_{3}$ is reported to have $2.53 \mathrm{eV}$ (Wang et al., 2016), whereas the conduction band is around $-0.1 \mathrm{eV}$ and the valence band is at $\sim 2.43 \mathrm{eV}$. So, it can be said that the band position of $\mathrm{CoTiO}_{3}$ lies in between the valence band and the conduction band of $\mathrm{TiO}_{2}$.

The photodegradation efficiency of the pure $\mathrm{TiO}_{2}$ and $\mathrm{CoTiO}_{3}-\mathrm{TiO}_{2}$ composite samples were measured in the presence of visible light (Figure 7). The R6G dye removal efficiencies were found to be $9 \%$ and $56 \%$ for pure $\mathrm{TiO}_{2}$ and $\mathrm{CoTiO}_{3}-\mathrm{TiO}_{2}$ composite nanofibers, respectively, within $5 \mathrm{~h}$ of the photocatalytic reaction. The better efficiency shown by the composite was mainly due to their photoabsorption properties in the presence of visible light. However, the dye removal efficiency of composite nanofibers was not very high as expected. This may be due to the fact that the band positions of $\mathrm{CoTiO}_{3}$ lies in middle of the valence band and the conduction band of $\mathrm{TiO}_{2}$, which makes it difficult to transfer photoexcited charges to $\mathrm{TiO}_{2}$ - and which ultimately leads to the decrease in the efficiency of a composite.

Figure 6. UV-Vis DRS spectra synthesized: (a) $\mathrm{TiO}_{2}$; and (b) $\mathrm{CoTiO}_{3}-\mathrm{TiO}_{2}$ composite nanofibers

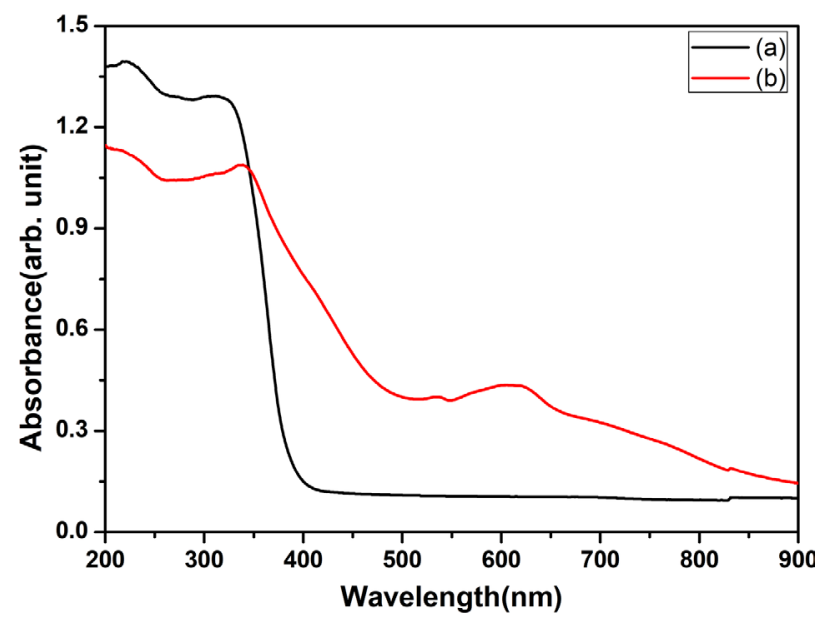


Figure 7. Photocatalytic activity of synthesized: (a) $\mathrm{CoTiO}_{3}-\mathrm{TiO}_{2}$ composite; and (b) $\mathrm{TiO}_{2}$ composite nanofibers for $\mathrm{R} 6 \mathrm{G}$ degradation

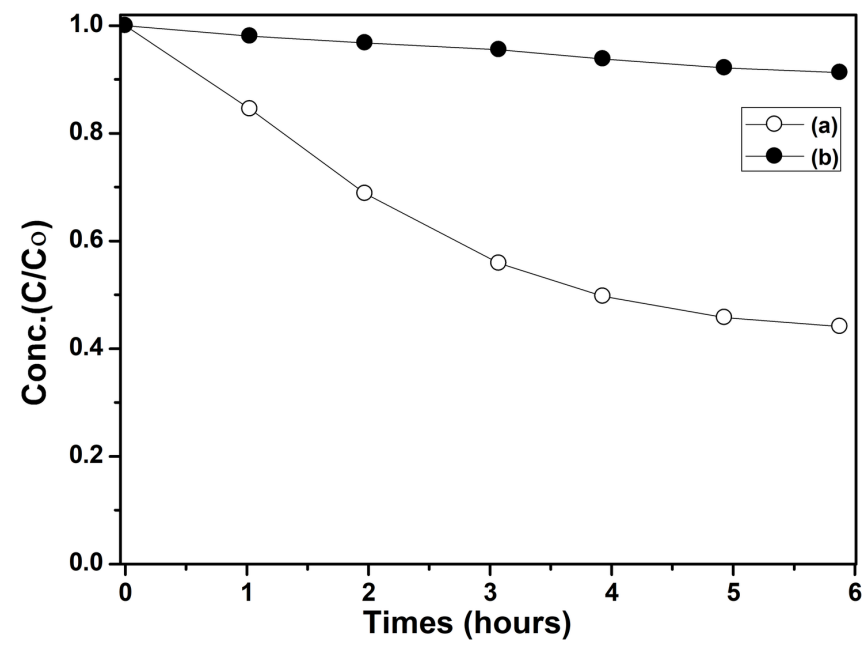

\section{CONCLUSION}

$\mathrm{CoTiO}_{3}-\mathrm{TiO}_{2}$ composite nanofibers were successfully prepared by electrospinning. The surface structure and the crystal formation of the samples were examined by different methods. The $\mathrm{CoTiO}_{3}$ $\mathrm{TiO}_{2}$ composite nanofibers were prepared by means of a simple and cost-effective single-step method. $\mathrm{The} \mathrm{CoTiO}_{3}-\mathrm{TiO}_{2}$ composite nanofibers demonstrated better activity than the pure $\mathrm{TiO}_{2}$ nanofibers did with regard to the degradation of R6G dye in the presence of visible light. The superior degradation efficiency of the $\mathrm{CoTiO}_{3}-\mathrm{TiO}_{2}$ composite nanofibers is primarily due to the heterojunctional interaction of $\mathrm{CoTiO}_{3}$ and $\mathrm{TiO}_{2}$ as well as to the low band energy of the composite photocatalyst. Nonetheless, the degradation efficiency of the composite nanofibers needs to be amplified further. This problem can be studied by doping with another element (such as $\mathrm{Cu}$ or $\mathrm{Cr}$ ) in further study and can be applied to other applications (adsorption; sensing, etc.). 


\section{REFERENCES}

Abdi, J., Yahyanezhad, M., Sakhaie, S., Vossoughi, M., \& Alemzadeh, I. (2019). Synthesis of porous TiO2/ZrO2 photocatalyst derived from zirconium metal organic framework for degradation of organic pollutants under visible light irradiation. Journal of Environmental Chemical Engineering, 7(3), 103096. doi:10.1016/j.jece.2019.103096

Chanhom, P., Charoenlap, N., Manipuntee, C., \& Insin, N. (2019). Metalloporphyrins-sensitized titania-silicairon oxide nanocomposites with high photocatalytic and bactericidal activities under visible light irradiation. Journal of Magnetism and Magnetic Materials, 475, 602-610. doi:10.1016/j.jmmm.2018.11.090

Chen, D., Jiang, Z., Geng, J., Wang, Q., \& Yang, D. (2007). Carbon and nitrogen co-doped TiO2 with enhanced visible-light photocatalytic activity. Industrial \& Engineering Chemistry Research, 46(9), 2741-2746. doi:10.1021/ie061491k

Choi, S. K., Kim, S., Lim, S. K., \& Park, H. (2010). Photocatalytic comparison of TiO2 nanoparticles and electrospun TiO2 nanofibers: Effects of mesoporosity and interparticle charge transfer. The Journal of Physical Chemistry C, 114(39), 16475-16480. doi:10.1021/jp104317x

Chuang, S.-H., Gao, R.-H., Wang, D.-Y., Liu, H.-P., Chen, L.-M., \& Chiang, M. Y. (2010). Synthesis and Characterization of Ilmenite-Type Cobalt Titanate Powder. Journal of the Chinese Chemical Society (Taipei), 57(4B), 932-937. doi:10.1002/jccs.201000129

Guan, S., Watabe, T., Hao, L., Yoshida, H., Cheng, Y., Zhou, K., \& Lu, Y. (2019). Enhanced photocatalytic activity of potassium-doped titania photocatalyst films with nanosheet structure. Materials Letters, 242, $174-178$. doi:10.1016/j.matlet.2019.01.136

Hashemian, S., \& Foroghimoqhadam, A. (2014). Effect of copper doping on CoTiO3 ilmenite type nanoparticles for removal of congo red from aqueous solution. Chemical Engineering Journal, 235, 299-306. doi:10.1016/j. cej.2013.08.089

Hendrix, Y., Lazaro, A., Yu, Q. L., \& Brouwers, H. J. H. (2019). Influence of synthesis conditions on the properties of photocatalytic titania-silica composites. Journal of Photochemistry and Photobiology A Chemistry, 371, 25-32. doi:10.1016/j.jphotochem.2018.10.040

Ida, S., Wilson, P., Neppolian, B., Sathish, M., Karthik, P., \& Ravi, P. (2019). Ultrasonically aided selective stabilization of pyrrolic type nitrogen by one pot nitrogen doped and hydrothermally reduced graphene oxide/ titania nanocomposite (N-TiO2/N-RGO) for H2 production. Ultrasonics Sonochemistry, 57, 62-72. doi:10.1016/j. ultsonch.2019.04.041 PMID:31208620

Ilieva, M., Nakova, A., \& Tsakova, V. (2012). $\mathrm{TiO}_{2} / \mathrm{WO}_{3}$ hybrid structures produced through a sacrificial polymer layer technique for pollutant photo-and photoelectrooxidation under ultraviolet and visible light illumination. Journal of Applied Electrochemistry, 42(2), 121-129. doi:10.1007/s10800-011-0378-9

Jiang, J., Zhu, J., Ai, W., Fan, Z., Shen, X., Zou, C., \& Yu, T. et al. (2014). Evolution of disposable bamboo chopsticks into uniform carbon fibers: A smart strategy to fabricate sustainable anodes for Li-ion batteries. Energy \& Environmental Science, 7(8), 2670-2679. doi:10.1039/C4EE00602J

Jiang, W., Zong, X., An, L., Hua, S., Miao, X., Luan, S., \& Sun, Z. et al. (2018). Consciously constructing heterojunction or direct Z-scheme photocatalysts by regulating electron flow direction. ACS Catalysis, 8(3), 2209-2217. doi:10.1021/acscatal.7b04323

Ke, S., Cheng, X., Wang, Q., Wang, Y., \& Pan, Z. (2014). Preparation of a photocatalytic TiO2/ZnTiO3 coating on glazed ceramic tiles. Ceramics International, 40(6), 8891-8895. doi:10.1016/j.ceramint.2014.01.027

Li, Y., Yan, X., Yan, W., Lai, X., Li, N., Chi, Y., \& Li, X. et al. (2013). Hierarchical tubular structure constructed by mesoporous $\mathrm{TiO} 2$ nanosheets: Controlled synthesis and applications in photocatalysis and lithium ion batteries. Chemical Engineering Journal, 232, 356-363. doi:10.1016/j.cej.2013.07.124

Luna, M., Gatica, J. M., Vidal, H., \& Mosquera, M. J. (2019). One-pot synthesis of Au/N-TiO2 photocatalysts for environmental applications: Enhancement of dyes and NOx photodegradation. Powder Technology, 355, 793-807. doi:10.1016/j.powtec.2019.07.102 
Mahieu, C., Puzenat, E., Geantet, C., Cardenas, L., \& Afanasiev, P. (2019). Titania-supported transition metals sulfides as photocatalysts for hydrogen production from propan-2-ol and methanol. International Journal of Hydrogen Energy, 44(33), 18038-18049. doi:10.1016/j.ijhydene.2019.05.080

Mahy, J. G., Paez, C. A., Carcel, C., Bied, C., Tatton, A. S., Damblon, C., \& Lambert, S. D. et al. (2019). Porphyrin-based hybrid silica-titania as a visible-light photocatalyst. Journal of Photochemistry and Photobiology A Chemistry, 373, 66-76. doi:10.1016/j.jphotochem.2019.01.001

Mao, W., Bao, K., Cao, F., Chen, B., Liu, G., Wang, W., \& Li, B. (2017). Synthesis of a CoTiO3/BiOBr heterojunction composite with enhanced photocatalytic performance. Ceramics International, 43(3), 3363-3368. doi:10.1016/j.ceramint.2016.11.180

Ouyang, J., Chang, M., \& Li, X. (2012). CdS-sensitized $\mathrm{ZnO}$ nanorod arrays coated with TiO2 layer for visible light photoelectrocatalysis. Journal of Materials Science, 47(9), 4187-4193. doi:10.1007/s10853-012-6273-x

Pan, X., Zhao, Y., Liu, S., Korzeniewski, C. L., Wang, S., \& Fan, Z. (2012). Comparing graphene-TiO2 nanowire and graphene-TiO2 nanoparticle composite photocatalysts. ACS Applied Materials \& Interfaces, 4(8), 3944-3950. doi:10.1021/am300772t PMID:22779922

Park, J. H., Kim, S., \& Bard, A. J. (2006). Novel carbon-doped TiO2 nanotube arrays with high aspect ratios for efficient solar water splitting. Nano Letters, 6(1), 24-28. doi:10.1021/n1051807y PMID:16402781

Pylnev, M., \& Wong, M.-S. (2019). Comparative study of photocatalytic deactivation of pure and black titania thin films. Journal of Photochemistry and Photobiology A Chemistry, 378, 125-130. doi:10.1016/j. jphotochem.2019.04.020

Ratova, M., Tosheva, L., Kelly, P. J., \& Ohtani, B. (2019). Characterisation and properties of visible light-active bismuth oxide-titania composite photocatalysts. Sustainable Materials Technology.

Sheydaei, M., Zangouei, M., \& Vatanpour, V. (2019). Coupling visible light sono-photocatalysis and sono-enhanced ultrafiltration processes for continuous flow degradation of dyestuff using N-doped titania nanoparticles. Chemical Engineering and Processing-Process Intensification, 143, 107631. doi:10.1016/j. cep.2019.107631

Singh, M., Qin, F., Ordoñez, O. I. P., Yang, W., Bao, J., Genc, A., \& Hernandez, F. C. R. et al. (2019). (in press). Unusual catalytic activity of $\mathrm{TiO} 2-\mathrm{CoTiO} 3$ under $1064 \mathrm{~nm}$ pulsed laser illumination. Catalysis Today. doi:10.1016/j.cattod.2019.06.081

Srisasiwimon, N., Chuangchote, S., Laosiripojana, N., \& Sagawa, T. (2018). TiO2/Lignin-based carbon composited photocatalysts for enhanced photocatalytic conversion of lignin to high value chemicals. ACS Sustainable Chemistry \& Engineering, 6(11), 13968-13976. doi:10.1021/acssuschemeng.8b02353

Tahir, M., \& Amin, N. A. S. (2013). Advances in visible light responsive titanium oxide-based photocatalysts for $\mathrm{CO}_{2}$ conversion to hydrocarbon fuels. Energy Conversion and Management, 76, 194-214. doi:10.1016/j. enconman.2013.07.046

Tasbihi, M., Schwarze, M., Edelmannová, M., Spöri, C., Strasser, P., \& Schomäcker, R. (2019). Photocatalytic reduction of $\mathrm{CO} 2$ to hydrocarbons by using photodeposited Pt nanoparticles on carbon-doped titania. Catalysis Today, 328, 8-14. doi:10.1016/j.cattod.2018.10.011

Toubal, B., Bensaha, R., \& Yakuphanoglu, F. (2017). The influence of copper-cobalt co-doping on optical and electrical properties of nanostructures TiO 2 thin films prepared by sol-gel. Journal of Sol-Gel Science and Technology, 82(2), 478-489. doi:10.1007/s10971-017-4337-8

Wang, Q., Guo, Q., Wang, L., \& Li, B. (2016). The flux growth of single-crystalline $\mathrm{CoTiO}_{3}$ polyhedral particles and improved visible-light photocatalytic activity of heterostructured $\mathrm{CoTiO}_{3} / \mathrm{gC}_{3} \mathrm{~N}_{4}$ composites. Dalton Transactions (Cambridge, England), 45(44), 17748-17758. doi:10.1039/C6DT03449G PMID:27766332

Yan, X., He, J., Evans, D. G., Zhu, Y., \& Duan, X. (2004). Preparation, characterization and photocatalytic activity of $\mathrm{TiO}_{2}$ formed from a mesoporous precursor. Journal of Porous Materials, 11(3), 131-139. doi:10.1023/ B:JOPO.00000ิ38008.86521.9a 
Yoon, Y. H., Lee, S. Y., Gwon, J. G., Cho, H. J., Wu, Q., Kim, Y. H., \& Lee, W. H. (2018). Photocatalytic performance of highly transparent and mesoporous molybdenum-doped titania films fabricated by templating cellulose nanocrystals. Ceramics International, 44(14), 16647-16653. doi:10.1016/j. ceramint.2018.06.091

Zhang, Y., Xiong, X., Han, Y., Zhang, X., Shen, F., Deng, S., \& Peng, H. et al. (2012). Photoelectrocatalytic degradation of recalcitrant organic pollutants using TiO2 film electrodes: An overview. Chemosphere, 88(2), 145-154. doi:10.1016/j.chemosphere.2012.03.020 PMID:22483728

Zhu, X., Anzai, A., Yamamoto, A., \& Yoshida, H. (2019). Silver-loaded sodium titanate photocatalysts for selective reduction of carbon dioxide to carbon monoxide with water. Applied Catalysis B: Environmental, 243, 47-56. doi:10.1016/j.apcatb.2018.10.021 